\title{
Las prioridades del enfermo y su familia
}

\author{
Andrés Aberasturi \\ Periodista
}

¿Qué esperan los familiares de su médico en el futuro? Yo puedo hablar con la experiencia de ser el padre de un paciente que lleva 25 años en seguimiento por los médicos debido a una enfermedad crónica. Vaya por delante que reconozco que la mayoría de los médicos lo hacen bien, pero en ocasiones algunos dejan mucho que desear. Describiría lo que se me pide desglosándolo en seis puntos.

\section{LOS FAMILIARES ESPERAMOS LA CURACIÓN.}

Cuando alguno tiene un familiar enfermo espera de los médicos la curación, el milagro. Uno no sabe, no puede hacer nada para que se produzca esa curación, por eso se deposita mucha confianza en los facultativos. Uno tiene que decidir, tiene que opinar, pero en la base de esas responsabilidades personales, que son ineludibles, coexiste también la esperanza en los medios humanos y materiales para que el paciente se cure. Esperamos que se pongan todos los medios. Esperamos que el médico haga lo mejor para el enfermo. A veces no sabemos que es lo mejor, no tenemos elementos de juicio suficientes para juzgar que es lo mejor y existe el abandono en la decisión del médico, confiando que adoptará las mismas decisiones y actuaciones que si se tratase de un familiar propio. La actitud que muestra el médico respecto a las posibilidades de llegar a un diagnóstico y a un tratamiento oportuno mantienen el ánimo de los familiares. Éstos agradecen ver que se están poniendo todos los medios. Por todo lo expuesto, no nos interesa a los familiares los asuntos administrativos, aunque sabemos que son necesarios, no nos importa el día de la semana que es, la hora del día, el mes, los turnos de guardia, si está roto un aparato, si hay lista de espera, nosotros queremos que por el paciente, que es familiar nuestro, se haga lo que haya que hacer, lo mejor que se pueda y pueda curarse.

\section{ESPERAMOS UN DIAGNÓSTICO INEQUÍVOCO. COMUNICACIÓN Y CLARIDAD. QUE ENTIENDAN LA INFORMACIÓN.}

En no pocas ocasiones los médicos no logran que las familias sepan exactamente lo que va a llevar consigo el diagnóstico de su familiar enfermo. Pueden haber llegado a un diagnóstico exacto, muchas veces de modo brillante, logrado con tenacidad, poniendo todos los medios materiales y dedicando horas de esfuerzo intelectual a ello, pero cuando lo cuentan, no lo hacen bien: dicen el nombre de la enfermedad, describen el lugar donde está la lesión, a qué puede ser debida si se sabe y qué tratamiento se ha comenzado; otras veces, quizás pueden explicar de modo genérico de qué se trata, pero es frecuente que no expongan con claridad las consecuencias que ese diagnóstico lleva consigo para el futuro, si el paciente podrá volver a caminar, a hablar, si podrá repetirse el motivo del ingreso. La angustia que genera la imprecisión sobre la enfermedad de un familiar es muy grande. En ocasiones el diagnóstico no está establecido con certeza, hay que esperar la evolución, no merece la pena hacer exploraciones molestas al paciente a juicio de los médicos o por otras razones; en estos casos se agradece la claridad en la explicación de porqué no se sabe lo que pasará en el futuro y qué sería lo esperable, considerando si se quiere los posibles "escenarios" que podrían aparecer dependiendo de una u otra circunstancia. La comunicación falla con frecuencia en los médicos. Suelen ser personas brillantes, capaces, estudiosas, dedicadas, pero no son capaces de comunicarse con la familia de un enfermo y no logran hacerse entender. Considero una carencia actual de los médicos en España las habilidades de comunicación, que hay que aprenderlas. Debería haber una asignatura obligatoria en las facultades de Medicina de Comunicación. Lo considero imprescindible.

\section{DELICADEZA ADEMÁS DE LA CLARIDAD.}

Por esa misma falta de habilidades de comunicación, en ocasiones no se proporciona la información con delicadeza. A veces se agradecería que los médi- 
cos no fuesen tan tajantes en el primer momento, esperar resultados, evoluciones favorables posibles. Se exponen las cosas con tal crudeza que es difícil de asumir por el familiar de un paciente, que espera la curación y "el milagro".

\section{CADA ENFERMO ES EL ÚNICO ENFERMO.}

Cada paciente es único, para la familia, muchas veces, el único enfermo. Tiene nombre, una situación familiar concreta, y también una situación social: vive en una localidad determinada, trabaja si es el caso, tiene amigos, en definitiva, tiene una riqueza como persona en sí misma considerada muy grande. La enfermedad es un añadido a todo lo que una persona tiene entre manos a diario, de modo diferente si es un paciente crónico, y en este caso cada episodio de agudización es diferente. Por otra parte, el hecho de que la enfermedad del paciente sea frecuente, y muchos pacientes ingresen con la misma patología a diario, unido al ritmo de trabajo y las prisas hacen que el médico no muestre un interés ante el problema que le plantea el enfermo y de este modo no se sea delicado. Modos de denominar a un enfermo como el "de la cama 517", o con la patología "el de la hemorragia que ingresó anoche", no son por desgracia infrecuentes. Un paciente y su familia desean que se les trate bien, "como si fuese el único paciente que existe".

\section{DIGNIDAD MANTENIDA ALREDEDOR. ESTÉTICA.}

Junto con lo anterior hay una serie de aspectos relacionados con la dignidad. Cuando un paciente está ingresado, está inerme, expuesto a hacer todo lo que le digan. En ocasiones, por la edad, por su situación mental, o por otras causas, no sabe cuidarse, ha perdido el sentido de lo estético, del "saber estar"... Aspectos como la ropa que tienen puesta los enfermos en los centros, que sea de su talla, el modo en que se realizan las exploraciones, una conversación con el paciente de la cama del al lado en la que se tratan temas de intimidad, deben ser cuidados. La dignidad del paciente debe cuidarse, aunque él no se dé cuenta.

\section{ASOCIACIONES DE AYUDA, "SUSTO AL SALIR", ASOCIACIONES DE AYUDA, ASISTENCIA SOCIAL.}

Cuando el paciente sale del hospital, en mayor o menor grado, dependiendo de la enfermedad de que se trate, la familia necesita tener clara la conducta a seguir de manera ambulatoria. Muchas veces aspectos tan esenciales como el régimen de vida, posibilidad de ejercicio, dieta que ha de hacer el paciente, complicaciones que pueden presentarse y modo de solucionarlas, no se indican con claridad. Será necesario en ocasiones el apoyo de trabajadores sociales. Para este aspecto como para otros, en los pacientes crónicos, hay demasiadas barreras administrativas que podrían superarse. En concreto, podría mejorarse en los pacientes crónicos la comodidad para obtener una medicación que tiene prescrita para tomar de por vida, que obliga a desplazamientos a los servicios de salud para recoger las recetas; en este mismo sentido, la obtención de pañales y la solicitud de los medicamentos que necesitan visado de los inspectores. 